\title{
Tempos Pandêmicos: A Covid-19 E Seus Impactos Para A População Socialmente Vulnerável
}

\section{Pandemic Times: The Covid-19 And Its Impacts On The Socially Vulnerable Population}

DOI: $10.46919 / \operatorname{archv2n3-005~}$

Recebimento dos originais: 01/05/2021

Aceitação para publicação: 30/06/2021

\author{
Juliana Soares Laudelino Santos \\ Psicóloga, Universidade Federal de Alagoas/UFAL \\ Residente Multiprofissional em Saúde do Adulto e do Idoso: Hospital Universitário Professor Alberto \\ Antunes - HUPAA/UFAL \\ Endereço: Avenida Lourival Melo Mota, S/N, Tabuleiro do Martins, Maceió - Alagoas, CEP: 57072900 \\ E-mail: julianalaudelino@gmail.com
}

\section{RESUMO}

A terceira década deste milênio iniciou com um desafio ainda não visto por nossa espécie: Uma pandemia sem precedentes que tende a permanecer por tempo indeterminado. Assim, a COVID-19 se propagou ligeiramente no mundo inteiro, sua expansão trouxe impactos econômicos, sociais e para a saúde. Diante disso, o objetivo deste trabalho foi o de investigar, analisar e discutir sobre os impactos trazidos pelo novo Coronavírus para a sociedade, sobretudo para o grupo de pessoas que possuem poucos recursos financeiros, de moradia, saúde e educação, ou seja, o grupo de pessoas socialmente vulneráveis. Quanto aos aspectos metodológicos, este trabalho trata-se de uma pesquisa qualitativa e bibliográfica. na qual realizamos um levantamento das produções existentes no nosso tema de interesse. Constatou-se nos resultados que pandemia acarretou danos a toda a população, sendo a população vulnerável socialmente a maior impactada pelos efeitos, havendo, portanto, a necessidade de serem impostas boas estratégias de igualdade e reconhecimento na democratização das possibilidades de dar continuidade à vida durante a pandemia e após o término.

Palavras-chave: Pandemia, Coronavírus, Pessoas Socialmente Vulneráveis.

\begin{abstract}
The third decade of this millennium began with a challenge not yet seen by our species: An unprecedented pandemic that tends to remain indefinitely. Thus, COVID-19 spread slightly throughout the world, its expansion brought economic, social and health impacts. Therefore, the objective of this work was to investigate, analyze and discuss the impacts brought by the new Coronavirus to society, especially for the group of people who have few financial, housing, health and education resources, that is, the group of socially vulnerable people. As for the methodological aspects, this work is a qualitative and bibliographic research. in which we carry out a survey of existing productions in our topic of interest. It was found that a pandemic caused damage to the entire population, with the socially vulnerable population being the largest impacted by the effects, thus, there is a need to impose good equality and recognition strategies in the democratization of the possibilities of giving continuity of life during the pandemic and after termination.
\end{abstract}

Keywords: Pandemic, Coronavirus, Socially Vulnerable People. 


\section{INTRODUÇÃO}

Segundo Lima (2020) o Coronavírus é um vírus zoonótico, um RNA vírus da ordem Nidovirales, da família Coronaviridae. O autor pontua que os tipos de coronavírus conhecidos até o momento são: alfa coronavírus HCoV-229E e alfa coronavírus HCoV-NL63, beta coronavírus HCoV-OC43 e beta coronavírus HCoV-HKU1, SARS-CoV (causador da síndrome respiratória aguda grave ou SARS), MERS$\mathrm{CoV}$ (causador da síndrome respiratória do Oriente Médio ou MERS) e SARS-CoV-2, um novo coronavírus descrito no final de 2019 após casos registrados na China. Este provoca a doença chamada de COVID-19.

Os sinais e sintomas clínicos do novo coronavírus são principalmente respiratórios, análogos a um resfriado, todavia podem causar infecção no trato respiratório inferior, como as pneumonias (SECRETARIA DA SAÚDE, 2020).

A partir da chegada da COVID-19 no Brasil, foram tomadas muitas medidas de controle e prevenção da doença, sendo a prática do distanciamento social a medida mais difundida pelas autoridades (BEZERRA, SILVA, SOARES, SILVA. 2020). Desse modo, A pandemia do Covid é uma preocupação para a saúde pública, pois afeta pessoas em todo o mundo, sobretudo aquelas que possuem menores rendas e estão em condições sociais desfavoráveis.

Nesse contexto, esta pesquisa tem o intuito de analisar e investigar através de uma revisão de literatura quais são os impactos trazidos pelo coronavírus, gerador da pandemia do COVID-19, sobretudo para essa camada mais desfavorecida. O Interesse pelo tema surgiu devido a experiência em atendimentos psicológicos realizados pela autora (enquanto psicóloga clínica) a um grande número de pessoas que pertencem a essa camada.

\section{METODOLOGIA}

No que se refere aos aspectos metodológicos, desenvolvemos este estudo com base na pesquisa qualitativa e bibliográfica, visando realizar um levantamento das produções existentes no nosso tema de interesse. A pesquisa bibliográfica é uma modalidade de estudo que se fundamenta em fontes de pesquisa e pela discussão de vários autores. Com isso, temos que esse tipo de pesquisa “[...] implica em um conjunto ordenado de procedimentos de busca por soluções, atento ao objeto de estudo, e que, por isso, não pode ser aleatório" (LIMA; MIOTO, 2007, p. 38).

Sobre os rumos de uma abordagem metodológica qualitativa Minayo (2012) pontua que esse é um tipo de pesquisa que tem um objeto de estudo com questões muito particulares. Desta forma, a pesquisa qualitativa reflete as realidades que não podem ser comensuradas, isto é, quantificadas e/ou traduzidas em números. 
A discussão se deu através de leituras de referenciais teóricos que se destacam em suas pesquisas relacionadas ao assunto, como Lima e Pires. Assim, com a finalidade de chegar ao objetivo proposto, foram selecionados cinco artigos científicos em português através de uma pesquisa virtual na base de dados Google Acadêmico, os quais foram selecionados após buscas fazendo uso da expressão "a pandemia da covid- 19 e seus impactos" e leituras sobre a temática.

\section{RESULTADOS E DISCUSSÕES}

A COVID-19 se propagou ligeiramente no mundo inteiro, sua expansão trouxe impactos econômicos, sociais e para a saúde. Essa doença progrediu em todos os continentes, por isso atribuiu a necessidade de contenção e isolamento de pessoas para diminuir o aumento do número de pessoas infectadas.

Diante disso houveram diversos interessados em contribuir na segurança, assistência e provimento de recursos necessários a diminuição dos casos e na mitigação de seus resultados na saúde dos indivíduos, como os governos, empresas, profissionais de diferentes especialidades.

Porém, as ações e políticas de prevenção da contaminação e da diminuição de danos infelizmente possuem dificuldades em alcançar as comunidades periféricas das cidades. Nessas localidades as condições sanitárias e a alta densidade populacional por metro quadrado geralmente são precárias, provocando uma ligeira contaminação pela COVID-19.

Assim, a população que se encontra em situação de vulnerabilidade social é a maior impactada pelos efeitos da pandemia da COVID-19, devido à falta e/ou insuficiência de recursos, estratégias de prevenção e/ou tratamento da doença em seus cotidianos "seja pela maior dificuldade de manter o isolamento social, o emprego e a renda, seja pelo menor acesso à saúde e ao saneamento básico” (Pires et al., 2020, p.01).

Além disso, a pobreza extrema é uma ferida exposta. Existem milhares de pessoas vivendo em condições precárias, subempregadas, que dependem do movimento, da circulação, para conseguir alguma renda, algo que garanta a sobrevivência (Calmon, 2020; Muniz et al., 2020). A maioria dessas pessoas são subalternizadas, encontrando-se numa condição desvantajosa na disputa do mercado de trabalho. Geralmente, esses sujeitos precisam usufruir das políticas sociais

Diante disso compreendemos que os grupos que vivenciam a maior pobreza estão mais expostas à COVID-19. À exemplo, os dados coletados pelo Departamento de Saúde da cidade de Nova York colocam que os bairros urbanos mais pobres da cidade estão sendo mais afetados, não necessariamente pelo número de casos, mas por um índice maior de gravidade, dada outras fragilidades associadas ao acesso de recursos necessários para tratamentos ou outras comorbidades que já atingem essa população (Pires et al., 2020).

Somado a isso, vivenciamos um momento de crise e emergência, com reflexos sociais, econômicos e na saúde física e mental das pessoas, principalmente as mais vulneráveis. As políticas e ações 
governamentais voltam-se para às possibilidades de contenção e mitigação dos efeitos biológicos e letais da doença. Em situações de confinamento e isolamento condicionados à pandemia, é relevante a necessidade de promoção de ações voltadas ao comportamento seguro, com destaque para o cumprimento de regras e ao autocuidado. Entretanto, neste momento de enfrentamento à contaminação, constata-se também a proliferação problemas na saúde mental das pessoas (Brooks et al., 2020).

Logo, durante os surtos de doenças, a ansiedade da comunidade pode aumentar após a primeira morte, o noticiamento de aumento pela mídia e um número crescente de novos casos. Assim, é provável que a quarentena em massa aumente substancialmente a ansiedade, por várias razões (LIMA et al.,2020).

Destarte, compreendemos que a pandemia ocasionou rigorosas mudanças na vida cotidiana da população, independente da faixa etária, trazendo danos para todos, porém maiores para aquelas camadas menos favorecidas economicamente.

Diante disso, consideramos necessário ativar melhores estratégias, serviços e recursos disponíveis na prevenção e resolução dos problemas colocados. Portanto, boas estratégias de igualdade e reconhecimento se fazem necessárias na democratização das possibilidades de dar continuidade à vida em meio a pandemia e após. Assim, através destas medidas de intervenções, a população poderá sofrer menos diante dos problemas, proporcionando desta forma uma melhor promoção de saúde e qualidade de vida.

\section{CONCLUSÃO}

Com base na literatura analisada, a pandemia do COVID-19 afetou pessoas nos mais diversos cenários mundiais, sobretudo àquelas que estão em situação desfavorável diante da sociedade.

Diante disso, defendemos a necessidade de maiores implantações de estratégias como a adoção de políticas socioeconômicas, expandindo o acesso a melhores condições de educação, moradia, saúde e renda, para assim melhorar a qualidade de vida dessa camada, não apenas durante a pandemia, mas também após o término desta. 


\section{REFERÊNCIAS}

BEZERRA, Anselmo César Vasconcelos; SILVA, Carlos Eduardo Menezes da; SOARES, Fernando Ramalho Gameleira and SILVA, José Alexandre Menezes da. Fatores associados ao comportamento da população durante o isolamento social na pandemia de COVID-19. Ciênc. saúde coletiva [online]. 2020, vol.25, suppl.1, pp.2411-2421. $\quad$ Epub June 05, 2020. ISSN 16784561. https://doi.org/10.1590/1413-81232020256.1.10792020.

Brooks, S. K., Webster, R. K., Smith, L. E., Woodland, L., Wessely, S., Greenberg, N., \& Rubin, G. J. (2020). The psychological impact of quarantine and how to reduce it: rapid review of the evidence. The Lancet. https://doi. org/10.1016/S0140-6736(20)30460-8.

Calmon, T. V. L. (2020). As condições objetivas para o enfrentamento ao COVID-19: abismo social brasileiro, o racismo, e as perspectivas de desenvolvimento social como determinantes. NAU Social, 11(20), 131-136.

LIMA, C. M. A. O. Informações sobre o novo coronavírus (COVID-19). Radiologia Brasileira, v. 53, n. 2, p. $2020 . \quad$ V-VI, 2 Disponível https://www.scielo.br/scielo.php?pid=S010039842020000200001\&script=sci_arttext\&tlng=pt.

Pires, L.L., Carvalho, L. \& Xavier, L.L. (2020). COVID-19 e Desigualdade no Brasil. Disponível em: https://www.researchgate.net/publication/340452851_COVID19_e_Desigualdade_no_Brasil. Acesso em 01 Fevereiro 2021.

Pires, R.R.C. (2020). Os efeitos sobre grupos sociais e territórios vulnerabilizados das medidas de enfrentamento à crise sanitária da COVID-19: propostas para o aperfeiçoamento da ação pública. Instituto de Pesquisa Econômica Aplicada - IPEA. 2020. Disponível em: http://www.ipea.gov.br/portal/publicacoes. Acesso em 01 Fevereiro 2020.

SECRETARIA DA SAÚDE, GOVERNO DO ESTADO DO CEARÁ. Plano estadual de contingência para resposta às emergências em saúde pública Novo Coronavírus (2019-nCoV). 2020. 